\title{
A classificação de acervos bibliográficos em bibliotecas de órgãos do judiciário: bens de consumo ou permanentes?
}

Nilcéia Lage Medeiros

Bibliotecária formada pela UFMG e Mestranda da Faculdade Novos Horizontes.

Alfredo Alves de Oliveira Melo

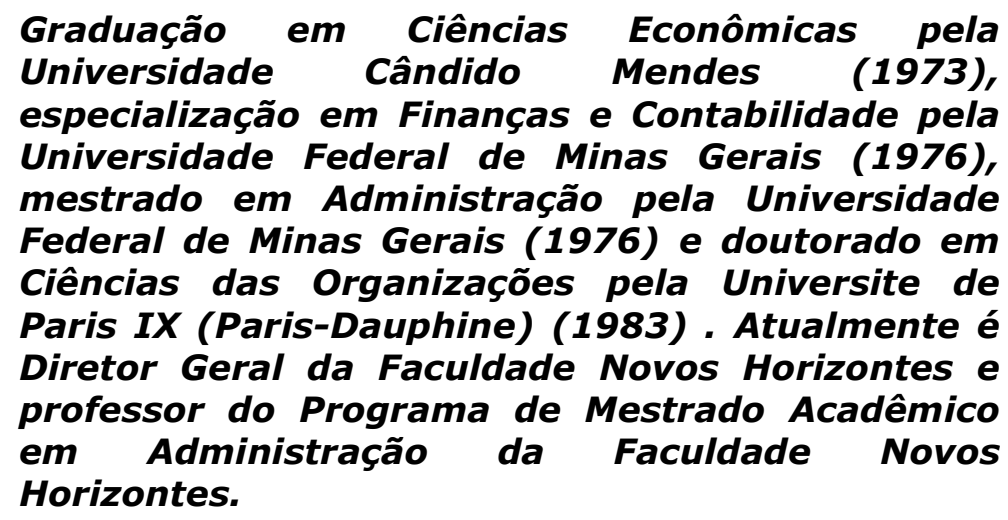

Ester Eliane Jeunon

Graduação em Psicologia pela Faculdade de Ciências Humanas Fundação Mineira de Educação, especialização em Administração de Recursos Humanos pelo União de Negócios e Administração, mestrado em Administração pela Universidade Federal de Minas Gerais e doutorado em Psicologia pela Universidade de Brasília. Atualmente é professor adjunto 3 da Pontifícia Universidade Católica de Minas Gerais e professor titular da Faculdade Novos Horizontes.

O artigo 18 da Lei no 10.753/2003, estabeleceu que, com a finalidade de controlar os bens patrimoniais das bibliotecas públicas, "o livro não é considerado material permanente". Foi realizada uma pesquisa no período de 26/02/2007 a 21/03/2007 objetivando analisar o que está sendo considerado na classificação dos acervos bibliográficos em bibliotecas de 33 órgãos do judiciário brasileiros (STF, STJ, CJF, TRFS, TST e TRTS), sendo que 22 deles colaboraram. Concluiu-se que a referida lei não deveria ter sido objeto de "conflitos e dilemas" já que bibliotecas destes órgãos são enquadradas como especializadas $e$, assim sendo, os livros devem ser 
classificados como bens permanentes. Também a STN emitiu parecer em 2003 reproduzindo o conceito de biblioteca pública e dispondo o que as bibliotecas que não se enquadram como públicas deveriam observar para a classificação. Ressalta-se que tal entendimento está claro, mas não está explicitado nem na lei e nem no parecer em questão. Detectou-se a necessidade de sanar as dúvidas e padronizar procedimentos relativos à classificação de acervos das bibliotecas desses órgãos, principalmente para os materiais indispensáveis ao desenvolvimento técnico gerencial específico ou à execução das atividades. Comunga-se com $o$ disposto na Mensagem $n^{\circ}$ 767192/2003, que devem ser observadas as peculiaridades e finalidades dos bens com vistas à classificação.

Palavras-chave: Acervos bibliográficos - bens permanentes; Acervos bibliográficos - bens de consumo; Acervos bibliográficos - bens de consumo de uso duradouro; Classificação contábil; Registro contábil; Tombamento; Descarte.

\section{The classification of bibliographic collections in libraries of Brazilian Judiciary bodies: consumer goods or permanent assets?}

Article 18 of the Law 10.753/2003 states that, aiming at controlling the assets of public libraries, "a book is not considered a permanent asset". A research with the objective of analyzing what is being considered in the classifications of the collections in the libraries of Brazilian Judiciary bodies was performed from 02/26/2007 to 03/21/2007. A total of 22 out of the 33 bodies (STF, STJ, CJF, TRFs, TST and TRTS) have provided information. It was concluded that such law should not have been an object of "conflicts and discussions" because libraries of these bodies are considered as specialized libraries, thus, their books should be classified as permanent assets. The STN also issued an opinion in 2003 explaining the definition of public library and stating that libraries that are not public must obey this classification. We emphasize that this understanding is clear but is not present in the law, neither in the above-mentioned opinion. There is a need to solve the doubts and to define standards for the 
procedures concerning the classification of the collections of the libraries of such bodies, especially for materials that are essential for the specific technical managerial development or accomplishment of activities. We agree with the Message 767192/2003 on that the specificities and purposes of the assets must be obeyed for classification.

Keywords: Bibliographical collections - consumer goods; Bibliographical collections - permanents goods; Bibliographical collections - consumables goods of durable use; Accounting classification; Accounting register; Discard.

Recebido em 30.03.2007 Aceito em 14.05.2007

\section{Introdução}

O acervo de uma biblioteca jurídica é composto de doutrinas, legislações, jurisprudências e materiais que sejam imprescindíveis à prática jurídica. Visando atender as necessidades informacionais, está a aquisição de materiais bibliográficos, entre as inúmeras rotinas da biblioteca. É por meio de aquisições periódicas que se pode chegar à criação e manutenção de um acervo atualizado que esteja em sintonia com as necessidades e interesses dos usuários (BRASIL, 1999), os objetivos da instituição e do estabelecimento de uma política de desenvolvimento de acervos. Além de adquirir, ressalta-se que é necessário implantar mecanismos eficientes para controle do material bibliográfico, enfatizando-se nesse trabalho especificamente os controles patrimonial e simplificado do material bibliográfico. É mister, nesses casos, ter em mente a racionalização e minimização na destinação de custos e utilização do material bibliográfico, compatíveis com as Políticas Públicas de Desenvolvimento Social e de Meio-Ambiente, bem como prever, regulamentar e padronizar procedimentos para o desfazimento desses materiais (BRASIL, 2003a).

A aquisição de materiais bibliográficos não vem se restringindo somente ao acervo da biblioteca, mas também na aquisição de obras de desenvolvimento técnico gerencial específico, ou indispensáveis à execução das atividades.

A preocupação em relação ao assunto pode ser melhor elucidada levando-se em consideração:

a) a necessidade de aperfeiçoar o controle dos recursos públicos e de verificar o cumprimento do princípio da eficiência, um dos princípios administrativos constitucionais, conforme determina o art. 37, caput, da Constituição Federal; 
b) a importância dos materiais bibliográficos para o suprimento das necessidades de informação dos profissionais no exercício das suas atividades;

c) a necessidade de otimizar a alocação de recursos financeiros empregados na atualização e manutenção do acervo das bibliotecas da Justiça Federal (BRASIL, 2004a).

A Lei no 10.753/2003, em seu artigo 18, dispõe que "com a finalidade de controlar os bens patrimoniais das bibliotecas públicas, 0 livro não é considerado material permanente", o que levou, conseqüentemente, à adoção de procedimentos a serem efetuados na aquisição e classificação e registro do material bibliográfico. Entretanto, tais procedimentos não sanaram por completo as dúvidas relativas a esse assunto, principalmente pelas bibliotecas que fazem parte da administração pública, que possuem diversos tipos de materiais em seus acervos, com peculiaridades e usos variados.

\section{CAPÍTULO V \\ DISPOSIÇÕES GERAIS}

Art. 16. A União, os Estados, o Distrito Federal e os Municípios consignarão, em seus respectivos orçamentos, verbas às bibliotecas para sua manutenção e aquisição de livros.

Art. 17. A inserção de rubrica orçamentária pelo Poder Executivo para financiamento da modernização e expansão do sistema bibliotecário e de programas de incentivo à leitura será feita por meio do Fundo Nacional de Cultura.

Art. 18. Com a finalidade de controlar os bens patrimoniais das bibliotecas públicas, o livro não é considerado material permanente. (BRASIL, 2003b, grifos nossos)

Além disso, a falta de padronização e entendimento das peculiaridades e finalidades dos materiais bibliográficos faz com que os setores financeiros e de contabilidade sintam dificuldades na classificação dos acervos bibliográficos.

No sentido de contribuir para a discussão do tema, este trabalho tem como objetivo analisar o entendimento e aplicação do disposto no artigo 18 da referida Lei no 10.753/2003, que dispõe sobre Política Nacional do Livro. A pesquisa realizada buscou reunir informações e documentos (legislações, atos normativos, entre outros) para análise de conteúdo dos pontos que estão sendo levados em consideração, ou não, para a classificação dos acervos bibliográficos como bens de consumo ou permanentes, em bibliotecas de órgãos do judiciário brasileiro.

Espera-se, com este trabalho, levantar pontos de discussão e atenção visando auxiliar os profissionais e comissões responsáveis pela área, na identificação, definição e implantação de classificações adaptadas 
às peculiaridades e finalidades dos materiais bibliográficos para adoção de procedimentos adequados à correta classificação contábil, seja em acervos de bibliotecas públicas como nas bibliotecas privadas.

Antes de tratar especificamente do tema desse artigo, faz-se necessário esclarecer os conceitos contábeis que poderão embasar as discussões sobre o mesmo.

\section{Conceitos contábeis}

Nas bibliotecas dos órgãos do judiciário, universo escolhido para a pesquisa, a contabilidade governamental objetiva "evidenciar todas as movimentações do patrimônio público e identificar os responsáveis por tais movimentações com vistas à prestação de contas" (SILVA, 2004, p. 198) estabelecendo então "regras de gestão patrimonial das entidades públicas para que as mesmas se realizem em perfeita ordem e sejam registradas sistematicamente" (SÁ; SÁ, 1995).

Elas são compostas de bens ${ }^{1}$ que fazem parte do patrimônio ${ }^{2}$ público que o Estado mantém para a realização dos serviços públicos relativos ao Poder Judiciário. Ressalta-se que bens públicos, vistos sob a ótiça jurídica, são os "de uso comum do povo" (Código Civil, 1916 apud SÁ; SÁ, 1995).

Para determinar a classificação dos materiais bibliográficos, que fazem parte do patrimônio da biblioteca, é essencial entender como a Contabilidade ${ }^{3}$ apresenta os conceitos relativos aos bens permanentes e de consumo, necessários à compreensão da discussão, assim como, de que forma os mesmos podem refletir na base teórica-científica para o planejamento mais adequado da contabilidade dos acervos bibliográficos. Salienta-se que o assunto não se esgota, já que podem surgir novas interpretações e classificações em função de "novos fatos ou operações que não estavam previstos na planificação inicial", bem como "a necessidade de aperfeiçoar o plano de contas, ou o processo de escrituração" (CONTABILIDADE..., 1998, p. 26).

Os bens do ativo permanente são aqueles tidos como de vida útil longa que se dividem em investimentos, diferido e imobilizado. Esse último se refere aos bens destinados à manutenção da atividade principal da empresa ou exercidos com essa finalidade, ou seja, aqueles que auxiliam a empresa "na consecução de sua atividade". São bens "que, dificilmente, se transformarão em dinheiro, pois não se destinam à venda, mas são utilizados como meio de produção" (MARION, 2004, p. 65-66).

1 "São os elementos materiais e imateriais ou nominais à disposição de uma entidade, que concorrem para que a mesma alcance seus objetivos" (GRECO, AREND, 1997, p. 33).

2 "Patrimônio, na sua condição de objeto da Contabilidade é, no mínimo, aquele juridicamente formalizado como pertencente à Entidade, com ajustes quantitativos e qualitativos realizados em consonância com os Princípios da própria Contabilidade" (IUDÍCIBUS, MARTINS, GELBCKE, 2003, p. 76).

3 "É a ciência que estuda os fenômenos patrimoniais [...]" (SÁ, SÁ, 1995, p. 96).

Já a Contabilidade Pública "constitui uma das subdivisões da Contabilidade Aplicada [...]. Seu campo de atuação é o das pessoas jurídicas de Direito Público [...] suas autarquias e entidades vinculadas [...] que utilizam recursos à conta do Orçamento Público" (PISCITELLI, TIMBÓ, ROSA, 1999, p. 21). 
Para Marion (2004), são necessárias três características concomitantes para que o bem seja classificado como permanente: natureza relativamente permanente; "ser utilizado na operação dos negócios; e não se destinar à venda" (p. 208). É imprescindível a compreensão de que o termo "permanente" ${ }^{4}$ é algo relativo, que pode ser visto sob dois prismas: praticamente "nenhum bem possui vida ilimitada dentro da empresa, sofrendo desgaste com o uso e, com o passar do tempo, obsolescência" (p. 208), assim sendo, possui vida útil limitada, ou seja, será útil "por um conjunto de períodos finitos, também chamados de períodos contábeis" (p. 211). Ressalta-se que em uma empresa, um bem pode ser classificado como permanente e não ser assim considerado em outra.

Por analogia, podem-se entender como bens de consumo, os que se esgotam, desgastam e se extinguem com maior rapidez que os bens permanentes. Para Greco e Arend (1997, p. 33) são os "aplicados diretamente na satisfação das necessidades".

Outros aspectos que se tornam relevantes, em relação ao patrimônio bibliográfico, são as definições de quais órgãos serão responsáveis pela aquisição, os tipos de controle ${ }^{5}$, registro ${ }^{6}$, inventário ${ }^{7}$ e tombamento ${ }^{8}$ de cada um desses materiais, bem como para onde os mesmos serão distribuídos, arquivados e estocados.

Para Piscitelli, Timbó e Rosa (1999), os bens de consumo são adquiridos, recebidos e estocados no almoxarifado (p. 290), já os permanentes (material de duração superior a dois anos), receberão números seqüenciais de registro patrimonial para identificação e inventário (p. 287), porém "quando o custo do controle for evidentemente superior ao risco de perda do bem, o material permanente de pequeno valor econômico poderá ser controlado por meio de simples relação (dispensado o tombamento)" (p. 288) e serão distribuídos mediante Termo de Responsabilidade (p. 288).

Piscitelli, Timbó e Rosa (1999) ressaltam que, por meio do inventário, podem-se detectar bens que já não estão tendo utilidade, são materiais inservíveis que serão classificados como ociosos, recuperáveis

4 "Reconhece-se, hoje, que a limitação da vida útil dos bens é devida a duas causas:

a) físicas - são o uso, o desgaste natural e a ação dos elementos da natureza;

b) funcionais - inadequação e obsoletismo. Estas causas estão ligadas aos efeitos do aparecimento de substitutos mais aperfeiçoados" (CONTABILIDADE..., 1998, p. 203).

5 "Controlado - o material que está sujeito ao tombamento e requer controle rigoroso de uso e responsabilidade pela sua guarda e conservação;

Relacionado - o material dispensado de tombamento, porém sujeito ao controle simplificado, por ser de pequeno valor econômico" (PISCITELLI, TIMBÓ, ROSA, 1999, p. 288).

6 "Gravar um fato de natureza patrimonial, escrever o que aconteceu com o patrimônio" (SÁ, SÁ, 1995, p. 422).

7 "Certificação da existência de elementos patrimoniais, sua classificação e valores" (SÁ; SÁ, 1995, p. 269).

"Os inventários na administração pública devem ser levantados não apenas por uma questão de rotina ou de disposição legal, mas também como medida de controle, tendo em vista que os bens nele arrolados não pertencem a uma pessoa física, mas ao Estado" (SILVA, 2004, p. 262).

8 "É a atribuição de número de registro patrimonial a cada bem individualizado; esta identificação é fundamental para o controle dos agentes responsáveis pela distribuição e guarda do citado material" (PISCITELLI, TIMBÓ, ROSA, 1999, p. 288). 
(orçado no máximo em $50 \%$ de seu valor de mercado), antieconômicos ou irrecuperáveis. Nas operações de gerenciamento de materiais, a administração irá destiná-los da forma "mais conveniente ao interesse público" por meio da transferência, cessão, alienação ou "outras formas de desfazimento (inutilização ou abandono)" (p. 291). Porém, se for "verificada a inconveniência ou a impossibilidade de alienação", será necessário iniciar um processo de desfazimento, determinando a sua baixa patrimonial ${ }^{9}$, bem como a sua inutilização ou abandono mediante "Termos de Inutilização ou de Justificativa de Abandono" (p. 293).

Pretende-se, a priori, situar o leitor em relação às bibliotecas que atendem especificamente os órgãos jurídicos, ou seja, o Direito, a informação e o acervo jurídico que atenderão o seu público-alvo.

\section{0 direito, a informação e o acervo jurídico}

O Direito é uma ciência interdisciplinar que se relaciona com "todas as áreas da vida humana" (REZENDE, 2003, p. 3 apud FULLIN, 2006, p. 32). Assim sendo, são os profissionais jurídicos "interessados por outras áreas do conhecimento que não a jurídica" (FULLIN, 2006, p. 32).

Os profissionais da área jurídica dependem de informações, pois elas são a matéria-prima básica em seu dia-a-dia de trabalho, principalmente da informação jurídica (FULLIN, 2006, p. 34).

Em pesquisas jurídicas, são acessados, basicamente, três tipos de informação: "produção jurídica do escritório, produção intelectual e a doutrina, legislação e jurisprudência" (BARRETO, 2002 apud PEREIRA, 2006, p. 31).

O acervo ${ }^{10}$ é a fonte de pesquisa. Ele é composto por materiais bibliográficos ${ }^{11}$, publicações ${ }^{12}$ e obras de referência ${ }^{13}$ necessárias para a realização das atividades (BRASIL, 2004a).

O acervo bibliográfico pertencente a um Tribunal é basicamente especializado em matéria jurídica de interesse institucional (BRASIL, 1999), sendo que tais publicações pertencem ao acervo da biblioteca. São elas:

a) obras de referência - enciclopédias, dicionários, códigos, vocabulários, legislação, etc.

b) obras especializadas ${ }^{14}$ e livros $^{15}$ nas diversas áreas das Ciências Jurídicas;

9 Baixa no imobilizado - "esgotamento do uso [...] desgaste" (SÁ; SÁ, 1995, p.47).

10 "Designação genérica de materiais destinados à pesquisa, disponíveis na Biblioteca" (BRASIL, 1999).

11 "Compreendem-se livros, obras de referência, periódicos, e-books, CD-ROMs, fitas de vídeo, DVDs e publicações oficiais" (BRASIL, 2004a).

12 "Documento impresso por qualquer processo mecânico, convencional ou não, destinado a tornar conhecidas informações específicas ou variadas, compreendendo livros, periódicos, jornais, folhetos, etc." (BRASIL, 1999).

13 "Compreendem-se dicionários, códigos, regulamentos, coletâneas de leis, entre outras obras de consulta" (BRASIL, 2004a).

14 Entre elas está a doutrina - "conjunto de princípios expostos nos livros de Direito, em que se firmam teorias ou se fazem interpretações sobre a ciência jurídica" (BRASIL, 1999). 


\section{c) periódicos ${ }^{16}$ da área jurídica e administrativa. (BRASIL, 1999)}

O profissional jurídico também necessita em seu cotidiano de obras bibliográficas indispensáveis à execução de suas atividades, bem como as de referência. Pode ser que elas tenham que ser consultadas várias vezes em um mesmo dia, o que faria com que esses profissionais tivessem que ir à biblioteca sempre que precisassem, ou então teriam que renovar a todo momento tais materiais. Por isso, estão sendo adotadas práticas onde tais profissionais poderão, facultativamente, solicitar a aquisição de materiais bibliográficos para suas salas e gabinetes, bem como a previsão de novas requisições de aquisição para as novas edições decorrentes de alterações no conteúdo (BRASIL, 1999).

A título de ilustração, os códigos são materiais bibliográficos muito manuseados e utilizados na prática jurídica, e torna-se imprescindível a aquisição de obras para que os profissionais estejam atualizados acompanhando as mudanças da legislação. Assim sendo, as novas edições atualizadas tornam-se necessárias para manter o acervo atualizado. Dessa forma, tais materiais, entre outros, são adquiridos e renovados para ficarem em cada uma das salas e gabinetes de juízes, promotores, advogados e demais funcionários dos órgãos do judiciário. Tais obras são classificadas, em alguns órgãos do judiciário, como bens de consumo. Há também previsão desse tipo de solicitação para unidades administrativas visando o desenvolvimento técnico gerencial específico de cada unidade (BRASIL. Superior Tribunal de Justiça, 2005). Para requisições de obras bibliográficas, o atendimento previsto inclui o empréstimo especial, pelo período de um ano, renovável a cada doze meses.

Algumas publicações, devido às suas peculiaridades, são exclusivamente para consulta no recinto da biblioteca (BRASIL, 1999). Assim sendo, existe previsão da não inclusão de enciclopédias e grandes coleções, devendo essas, integrarem unicamente o acervo da biblioteca para uso comum (BRASIL, 2005).

A compreensão de alguns tópicos, tais como, órgão a que a biblioteca é vinculada, objetivos, acervo e usuários, pode ser o embasamento para o início de discussões que tenham como finalidade o entendimento sobre o enquadramento de uma biblioteca como, por exemplo, pública ou especializada. Após a compreensão do exposto nessa

15 "Livro - é a publicação de textos escritos em fichas ou folhas, não periódica, grampeada, colada ou costurada, em volume cartonado, encadernado ou em brochura, em capas avulsas, em qualquer formato e acabamento; fascículos, publicações de qualquer natureza que representem parte de livro; materiais avulsos relacionados com o livro, impressos em papel ou em material similar; roteiros de leitura para controle e estudo de literatura ou de obras didáticas; álbuns para colorir, pintar, recortar ou armar; atlas geográficos, históricos, anatômicos, mapas e cartogramas; textos derivados de livro ou originais, produzidos por editores, mediante contrato de edição celebrado com o autor, com a utilização de qualquer suporte; livros em meio digital, magnético e ótico, para uso exclusivo de pessoas com deficiência visual; e livros impressos no Sistema Braille" (BRASIL, 2003C).

16 "Publicação seriada de periodicidade prefixada cujas unidades são geralmente constituídas por textos de autoria diversa" (BRASIL, 1999). 
seção, pretende-se, a seguir, tratar do enquadramento das bibliotecas de órgãos do judiciário: públicas ou especializadas? Talvez não seja dúvida para muitos, mas poderá não ser certeza para outros. Essa abordagem será tratada a seguir, e acredita-se que será de grande valia para o desenvolvimento do tema proposto neste trabalho.

\section{A biblioteca dos órgãos do judiciário: públicas ou especializadas?}

A biblioteca de um órgão do judiciário pode ser entendida como uma unidade de informação e apoio à pesquisa, que visa, então, atender às necessidades de informação e pesquisa dos usuários17 (BRASIL, 1999). Como "unidade de conhecimento humano" objetiva, principalmente:

embasar manifestações de pensamento jurisconsultos, advogados, legisladores, desembargadores, juízes e todos aqueles que lidam com a matéria jurídica, quando procuram estudar (do ponto de vista legal) ou regulamentar situações, relações e comportamentos humanos, ou ainda quando interpretam e aplicam dispositivos legais. (PASSOS, 2003, p. 2 apud FULLIN, 2006, p. 34).

Pelo disposto anteriormente, comunga-se da opinião de que bibliotecas de órgãos do judiciário sejam classificadas como especializadas, tal como disposto no conceito descrito a seguir:

É a biblioteca cujo acervo é centralizado num determinado assunto [...]. Geralmente, ela está vinculada a entidades especializadas, isto é, que se dedicam a estudos específicos. (A BIBLIOTECA, 1995, p. 15 apud ARRUDA; CHAGAS, 2002, p. 41)

Mesmo assim, encontrou-se biblioteca de tribunal definida como pública, conforme descrito a seguir:

Considerar como pública a biblioteca deste Tribunal Regional do Trabalho da $18^{a}$ Região, subordinada à Diretoria de Serviço de Arquivo e Jurisprudência. (BRASIL, 2004b, grifos nossos).

As dúvidas sobre o enquadramento ou não de bibliotecas de órgãos do judiciário, como públicas ou não, podem ser esclarecidas no conceito contido no Parecer da STN:

É uma instituição fundamental para o desenvolvimento educacional, cultural e social dos povos modernos. São centros de informação da comunidade instalados em lugar público, aberta a todos, em horário adequado para a comunidade, podendo-se ler livremente de tudo o que Ihe possa interessar em materiais bibliográficos (BRASIL, 2003c).

17 "O objetivo principal da Biblioteca é atender às necessidades de informação e pesquisa dos usuários do Tribunal" (BRASIL, 1999). 
Tal conceito vem de encontro ao exposto a seguir:

A biblioteca pública é plenamente aberta a toda a população local, é comum a todos e destina-se a coletividade. Deve ter todos os gêneros de obras que sejam do interesse da coletividade a que pertence e deve conter além de literatura em geral, informações básicas sobre a organização do governo e sobre serviços públicos em geral. As bibliotecas públicas podem ser, segundo o âmbito da coletividade em que estão implantadas, federais, estaduais e municipais (A BIBLIOTECA, 1995, p. 15 apud ARRUDA; CHAGAS, 2002, p. 41).

Assim sendo, pode-se concluir que o enquadramento da biblioteca, como pública ou privada, constitui-se em fato relevante para a adoção da classificação orçamentária e contábil dos materiais bibliográficos (como permanentes ou de consumo), bem como da modalidade de controle, seguindo-se então o disposto no art. 18 da Lei n. 10.753 ou no Parecer da STN.

Definidas questões conceituais e a classificação da biblioteca (pública ou especializada), pode-se então dar prosseguimento às discussões sobre o tema proposto para este trabalho.

\section{Aquisição e classificação contábil do material bibliográfico: bem de consumo ou permanente?}

A biblioteca deve manter atualizado o seu acervo, realizando periodicamente aquisições de publicações de interesse dos usuários (BRASIL, 1999).

A aquisição de materiais bibliográficos exige tomadas de decisão dos gestores, dentre as quais destacam-se:

a) aplicação e distribuição eqüitativa dos recursos financeiros para aquisição das coleções de maior relevância;

b) alteração de critérios de distribuição dos investimentos face a fatores imprevistos, como mudanças de demandas;

c) adoção de critérios para o registro das diferentes coleções tendo em vista o seu controle patrimonial (MACIEL, MENDONÇA, 2000, p. 21-22)

A eficácia da aquisição apóia-se em requisitos que levarão à maior qualidade dos serviços, tais como:

a) recebimento de recursos financeiros compatíveis com a demanda da seção;

b) conhecimento e acesso a todas as fontes de investimento institucionais ou não (MACIEL, MENDONÇA, 2000, p. 21-22)

Visando a correta classificação orçamentária e contábil dos materiais bibliográficos (permanentes ou de consumo), bem como escolha da 
modalidade de controle, é definido, a seguir, o que são materiais permanentes e de consumo.

Os materiais permanentes "são aqueles que, em razão de seu uso corrente, não perdem a identidade física e/ou têm durabilidade superior a dois anos" (BRASIL, 2006). Eles são "identificados mediante parâmetros excludentes, tomados em conjunto, tais como":

a) durabilidade, quando o material em uso normal perde ou tem reduzidas as suas condições de funcionamento, no prazo máximo de dois anos;

b) fragilidade, cuja estrutura esteja sujeita a modificação por ser quebradiço ou deformável, caracterizando-se pela irrecuperabilidade e/ou perda de sua identidade;

c) perecibilidade, quando sujeito a modificações (químicas ou físicas), ou que se deterioram ou perdem sua característica normal de uso;

d) incorporabilidade, quando destinado à incorporação a outro bem, não podendo ser retirado sem prejuízo das características do principal;

e) transformabilidade, quando adquirido para fim de transformação (BRASIL, 2003c);

Não será considerado bem permanente aquele:

f) caracterizado como livro, nos termos da lei no 10.753/2003, exceto obras raras, coleções especiais adquiridas em razão de seu valor histórico e cultural ou de alto custo de aquisição, que deverão receber registro patrimonial (BRASI, 2006).

Já os materiais de consumo são aqueles que,...

... em razão de seu uso corrente e da definição constante na Lei 4.320/1964, perdem normalmente sua identidade física, têm sua utilização limitada a dois anos e/ou têm sua vida útil reduzida de forma acelerada por desatualizações (BRASIL, 2006).

Os materiais bibliográficos "adquiridos para uso nas unidades administrativas que, no prazo de dois anos, se desgastem por manuseio ou se desatualizem, podem ser adquiridos como material de consumo"; já os destinados à biblioteca, como material de consumo sendo contabilizados na conta Material de Consumo de Uso Duradouro, "controlados por meio de relação-carga, verificando-se periodicamente as entradas e saídas" (BRASIL, 2004c).

Ressalta-se que o entendimento das peculiaridades e finalidades dos materiais bibliográficos constitui-se em fato relevante para a adoção de procedimentos adequados referentes à correta classificação orçamentária e contábil dos materiais bibliográficos (materiais permanentes ou de 
consumo), o que influenciará diretamente nas modalidades de controle e registro, que serão tratadas na próxima seção.

\section{Controle, registro ${ }^{18}$ e tombamento $^{19}$}

As legislações e atos normativos por vezes tratam de forma diferenciada os materiais classificados como permanentes dos de consumo, o que influencia no controle de cada um deles, que ora necessita de um controle patrimonial vinculado a uma unidade de administração do material e patrimônio, ou então um registro simplificado, não necessitando do número do registro patrimonial, tal como descrito a seguir.

As obras raras, livros históricos/artísticos/culturais e livros de alto custo e de reposição, adquiridos e classificados como material permanente (BRASIL. Ministério da Fazenda, 2003a) "ficando vinculadas, para efeito de controle e baixa, à unidade responsável pela administração do material e patrimônio" (BRASIL, 2005).

Os materiais bibliográficos adquiridos e classificados como material de consumo devem ser contabilizados (registro simplificado) como material de consumo de uso duradouro, e controlados por meio de relação-carga do material, verificando-se periodicamente a quantidade de itens requisitados de acordo com entradas e saídas (BRASIL, 2004c), não sendo necessário a identificação do número do registro patrimonial (BRASIL, 2003c).

São encontradas duas situações para a responsabilidade em relação ao controle patrimonial das obras de referência adquiridas para gabinetes e outras unidades administrativa: é realizado pela área de material e patrimônio (BRASIL, 2004c), ou deve ser realizado pela biblioteca.

Tais procedimentos irão influenciar nas atividades e controles relativos ao desbastamento e descarte do acervo, conforme descrito a seguir.

\section{Desbastamento ${ }^{20}$ e descarte do acervo bibliográfico}

Um acervo considerado de boa qualidade necessita ser desenvolvido racionalmente. Tal afirmativa se deve principalmente a fatores como o acúmulo de documentos nas estantes das bibliotecas, a produção documental extensa e a exigüidade de espaços físicos para comportar o acervo. A avaliação periódica de coleções pode sinalizar para a

18 "É a aposição de carimbo de identificação da Biblioteca nas publicações componentes do acervo, com vistas à identificação de sua propriedade" (BRASIL, 1999).

"Consiste na designação de um número de registro ou tombamento a cada novo exemplar de materiais, adquiridos pela UI, seguida da descrição de dados sobre sua aquisição e dos elementos de referência" (ROMANI, BORSZCZ, 2006. p. 36-37).

19 "É o arrolamento do bem, numerado em forma seqüencial, com o objetivo de identificá-lo para fins patrimoniais" (BRASIL, 1999).

20 "É o procedimento formal pelo qual a Administração promoverá a cessão, alienação, inutilização ou abandono de materiais" (BRASIL, 2003a). O Decreto 99.658/1990 versa sobre o desfazimento de material (BRASIL, 1990). 
necessidade de desbastamento ou descarte segundo critérios definidos na política de formação e desenvolvimento da coleção.

O processo de descarte de materiais em uma coleção, ou seja, a seleção negativa, consiste na seleção dos materiais que foram considerados desnecessários ou defasados (MACIEL, MENDONÇA, 2000). Alguns dos critérios para descarte são: inadequação, desatualização, desuso, desgaste (ROMANI, BORSZCZ, 2006) obsolescência, inadequação, condições físicas e duplicidade (BRASIL, 2004a).

Já o desbastamento (remanejamento) "consiste na retirada de documentos pouco utilizados pelos usuários, de uma coleção de uso freqüente, para outros locais" (MACIEL, MENDONÇA, 2000, p. 26).

A criação de acervos paralelos, tais como os chamados semi-ativos, encurtam o tempo de busca, sendo indispensáveis na gerência de acervos. Ressalta-se que é imprescindível a criação de uma comissão para tais funções (MACIEL, MENDONÇA, 2000).

O material inservível classifica-se em (BRASIL, 2006):

I - ocioso, quando não estiver sendo aproveitado, embora em perfeitas condições de uso;

II - recuperável, quando sua recuperação é possível a um custo não superior a cinqüenta por cento de seu valor de mercado;

III - antieconômico, quando sua manutenção for onerosa ou seu desempenho precário em virtude de uso prolongado, desgaste prematuro ou obsolescência;

IV - irrecuperável, material que por questões técnicas ou físicas (BRASIL. Tribunal Regional Federal da $4^{a}$ Região, 2003) não puder mais ser utilizado para o fim a que se destina, em razão da perda de suas características ou quando o custo da recuperação for superior a cinqüenta por cento de seu valor de mercado.

Ressalta-se que os processos de desbaste ou desfazimento "gerarão os necessários registros no sistema administrativo do órgão, bem como no Siafi", e que os "recursos provenientes da venda de material deverão ser recolhidos ao Tesouro Nacional, na forma da legislação em vigor" (BRASIL, 2006). O processo de desfazimento por inutilização ou abandono será documentado por meio dos "Termos de Inutilização ou de Justificativa de Abandono" (PISCITELLI, TIMBÓ, ROSA, 1999, p. 293).

Conceituados e descritos os processos, procedimentos e controles, a seguir será abordada a pesquisa realizada nos órgãos do judiciário.

\section{Metodologia}

Foi realizada pesquisa do tipo qualitativa objetivando identificar o entendimento e atendimento ao disposto no art. 18 da Lei no 10.753/2003 pelas bibliotecas dos órgãos do judiciário. Buscaram-se os diversos documentos, discussões, desdobramentos e temas relacionados e 
correlacionados à classificação contábil dos acervos. A pesquisa foi realizada no período de 26/02/2007 a 21/03/2007.

Para coleta de dados foi enviado e-mail ao universo escolhido para a pesquisa, ou seja, 33 bibliotecas de órgãos do judiciário (STF, STJ, CJF, os cinco TRFs, TST, e os 24 TRTs). Solicitou-se a colaboração no sentido de enviar materiais (opiniões, discussões, doutrinas, justificativas, regulamentos, legislações, atos normativos, entre outros) que embasam e determinam a classificação do acervo na biblioteca como bens de consumo ou permanentes.

Do universo de 33 bibliotecas, receberam-se respostas de 21, que colaboraram respondendo às perguntas e enviando, dentre outros, informações, documentos, legislações, atos normativos, discussões, e um documento foi conseguido via internet. Assim sendo, a amostra constituiuse de 22 bibliotecas $(66,66 \%)$.

Os dados foram analisados a partir do conteúdo do material encaminhado pelas bibliotecas. Foram analisadas as informações sobre o posicionamento adotado ou não pelo órgão do judiciário, bem como, as seguintes legislações e atos normativos: CJF - Resolução no 384/2004; CJF - Resolução no 420/2005; STJ - Ato no 47/2006; STJ - Ato no 213/2005; TRT 3 - Regulamento Interno da Biblioteca. Biblioteca Juiz Cândido Gomes de Freitas; TRT 18 - Portaria GP/GDG no 282/2004; TRT 22 - Ato GP no 152/2004; TRT 24 - Ato GP/DGCA/DI no 69/2004; TRF 4 IN-40-A-01/2003; TRF 4 - IN-42-D-01/1999; TST - Esclarecimentos sobre a classificação de material Bibliográfico; SIAFI - Mensagem $\mathrm{n}^{\circ}$ 767192/2003; SIAFI - Parecer $\mathrm{s} / \mathrm{n}^{\circ}$ de 19/12/2003; e a Lei $\mathrm{n}^{\circ}$ $10.753 / 2003$.

A análise de conteúdo é apresentada em duas partes: na primeira são elencados os diversos tipos de documentos e informações recebidas e, na segunda, o conteúdo temático dos mesmos.

\section{Apresentação dos resultados}

\subsection{Documentos e informações recebidas}

Nessa seção, apresentam-se os resultados sobre as informações e documentos recebidos. Buscou-se identificar a massa informacional e documentos norteadores da classificação e assuntos relacionados.

Os tipos de documentos e informações recebidas são descritos no TAB. 1. 
Tabela 1 - Tipos de documentos e informações recebidas

\begin{tabular}{l}
\hline \multicolumn{1}{c}{ Tipos } \\
\hline \hline Atos normativos e instruções normativas \\
Esclarecimentos do TST \\
Informações diversas* / Decisões discricionárias / Normas da biblioteca** e da \\
contabilidade \\
Lei no $10.753 / 2003$ \\
Parecer STN e Mensagem do SIAFI \\
Resoluções do CJF \\
\hline * Dois órgãos do judiciário em processo de disciplinamento da matéria; \\
Fonte: Dados da pesquisa.
\end{tabular}

Esclarecimentos do TST, o Parecer e a Mensagem do SIAFI estão direcionando o processo de classificação contábil. Isso demonstra que esses órgãos já se posicionaram em relação ao assunto. Em relação às resoluções do $\mathrm{CJF}$, atos e instruções normativas, pode-se verificar que vários órgãos do judiciário estão se baseando em normas próprias. Por último, observou-se que em vários órgãos do judiciário o assunto foi decidido de forma discricionária, e várias informações foram enviadas sem indicar a base normativa de sustentação.

Os documentos e informações recebidas sobre o disciplinamento normativo, ou não, da matéria na biblioteca, são apresentados na TAB. 2

TABELA 2- Disciplinamento da classificação contábil de materiais bibliográficos na biblioteca do órgão do judiciário

\begin{tabular}{lr}
\hline \hline \multicolumn{1}{c}{ Legislação/Norma... } & $\begin{array}{c}\text { No de } \\
\text { bibliotecas }\end{array}$ \\
\hline \hline Decisão discricionária/normas da biblioteca ou da contabilidade & 4 \\
Esclarecimentos do TST & 3 \\
Esclarecimentos do TST e as Resoluções do CJF & 1 \\
Legislação / Ato normativo da própria instituição & 3 \\
Legislação / Ato normativo da própria instituição e a Mensagem & \\
do SIAFI & 1 \\
Legislação / Ato normativo da própria instituição e as & \\
Resoluções do CJF & 1 \\
Lei no 10.753/2003 e o Parecer STN & 1 \\
Lei no 10.753/2003, sem instituir norma própria & 2 \\
Mensagem do SIAFI & 1 \\
Resoluções do CJF & 3 \\
\hline Total & $20^{*}$ \\
\hline * não foram computadas as duas bibliotecas que estão em processo de \\
disciplinamento.
\end{tabular}

A indicação de mais de um normativo por um órgão do judiciário, bem como, a de normativos contendo esclarecimentos e mensagens para sustentar a opção classificatória, indica a complexidade da questão e dificuldade de consenso sobre o tema. Ressalta-se que de um grupo de 22 bibliotecas, quatro se baseiam nos Esclarecimentos do TST e cinco nas 
Resoluções do CJF, indicando uma tendência pela utilização desses documentos.

As citações e remissões contidas nos documentos e informações recebidas são identificadas no TAB 3 .

TABELA 3 - Citações e remissões identificadas

\begin{tabular}{l}
\hline \multicolumn{1}{c}{ Tipos } \\
\hline Atos do CFC \\
Decreto no $99.658 / 1990$ \\
Jurisprudências \\
Lei no $10.753 / 2003$ \\
Lei no $8.666 / 1993$ \\
Regimentos internos \\
SIAFI \\
\hline Dados da pesquisa.
\end{tabular}

Fonte: Dados da pesquisa.

Desse quadro vale ressaltar que os estudos sobre o tema estão se baseando também no CFC, no SIAFI, na Lei de Licitações e em jurisprudências.

\subsection{Apresentação do conteúdo temático dos documentos e informações recebidas}

Nessa seção, o conteúdo está subdividido nos seguintes temas: definição da biblioteca como pública ou especializada, acervos e usuários; classificação dos materiais bibliográficos; departamentos responsáveis pelo material bibliográfico; obras classificadas como de desenvolvimento técnico-gerencial específico, ou indispensáveis à execução das atividades; desfazimento de materiais bibliográficos.

\subsubsection{Definição da biblioteca como pública ou especializada, acervos e usuários}

No TAB. 4, apresenta-se a definição da classificação da biblioteca como pública ou especializada.

TABELA 4 - Conceituação da biblioteca como pública ou privada

\section{Pontos identificados}

Definição da biblioteca como especializada*

Definição da biblioteca como pública

Definição de biblioteca pública e das aquisições que não se destinam a bibliotecas públicas

Necessidade de se avaliar se a biblioteca se enquadra no conceito de biblioteca pública

* Informado que "não se trata de bibliotecas públicas e sim especializadas".

Fonte: Dados da pesquisa 
É relevante a percepção variada que os órgãos do judiciário, mesmo sendo todos da esfera pública, têm sobre a tipologia da biblioteca (pública ou especializada). Este é um dos fatores que apontam para a discussão do assunto.

Em relação à indicação do acervo, como especializado ou não, podese observar no TAB.5:

TABELA 5 - Indicação do acervo como especializado ou de não se destinar à biblioteca pública

Pontos identificados

Definição de biblioteca pública e das aquisições que não se destinam a bibliotecas públicas Definição do acervo como especializado

Fonte: Dados da pesquisa.

A indicação do acervo com especializado, talvez seja, nesse caso, um indicativo de que a biblioteca deva ser classificada como especializada.

A definição explícita dos usuários da biblioteca está indicada no TAB.6.

TABELA 6 - Definição dos usuários da biblioteca

Usuários internos e externos ${ }^{21}$

Definições

Usuários potenciais (comunidade em geral)

Objetivo principal da biblioteca em atender o usuário do tribunal

Fonte: Dados da pesquisa.

A definição do objetivo principal de atendimento a usuários do tribunal sinaliza para o caráter especializado da biblioteca.

A partir dos dados apresentados nos Quadros de 6 a 10, entende-se que a definição da biblioteca como pública, ou não, seja o ponto de partida para as discussões sobre a classificação orçamentária e contábil, bem como a modalidade de controle dos acervos bibliográficos. A definição dos usuários e as diversas peculiaridades do acervo também são imprescindíveis na discussão visando um consenso sobre o tema.

\subsubsection{Classificação dos materiais bibliográficos ${ }^{22}$}

A classificação contábil do acervo bibliográfico é descrita no TAB.7

21 "Externos: dependentes dos usuários internos, filhos e cônjuges". (BRASIL, 2000).

22 Nem todos os dados a seguir serão apresentados sob a forma de quadros e tabelas. 
TABELA 7 - Classificação contábil do acervo, materiais bibliográficos, livros, códigos e periódicos

\begin{tabular}{l}
\hline \multicolumn{1}{c}{ Classificação contábil } \\
\hline \hline Material de consumo \\
Material de consumo (de uso duradouro) \\
Material de consumo (prestação de serviço) \\
Material permanente \\
Material permanente (dependendo da peculiaridade e do uso) \\
\hline \hline
\end{tabular}

Fonte: Dados da pesquisa.

Entre as mensagens recebidas, foi afirmado que "o acervo bibliográfico nos tribunais federais é considerado material permanente" e que "independente da atualização da monografia ela é considerada material permanente". Já em um documento foi identificada a classificação de consumo para bibliotecas públicas e permanentes para bibliotecas não públicas. Defende-se, nesse trabalho, a necessidade de discussões sobre tais temas, levando-se em consideração, principalmente, as peculiaridades e usos dos materiais bibliográficos.

Em um e-mail foi relatada, como uma vitória, a classificação de consumo para os códigos adquiridos para os gabinetes (obras de desenvolvimento técnico-gerencial específico ou indispensáveis à execução das atividades). É possível a adoção (tendência) desse procedimento pelos órgãos do judiciário? Esta é uma questão a se pesquisar e discutir.

Também foi relatada a classificação do livro como permanente e a despesa como de consumo. Há de se perquirir se alternativas como essa poderão levar a uma flexibilidade orçamentária maior para aquisição de obras, principalmente para as de desenvolvimento técnico-gerencial específico ou para as indispensáveis à execução das atividades.

O TAB. 8 relaciona os diversos tipos de materiais que devem ser a classificados contabilmente.

TABELA 8 - Classificação contábil dos diversos tipos de materiais bibliográficos

\begin{tabular}{l}
\hline \hline \multicolumn{1}{c}{ Tipos de materiais bibliográficos } \\
\hline \hline Enciclopédias \\
Grandes coleções \\
Livros \\
Livros (códigos) \\
Livros de alto custo de aquisição/reposição \\
Obras de desenvolvimento técnico gerencial específico \\
Obras de valor histórico, artístico e cultural \\
Obras indispensáveis à execução das atividades \\
Obras raras \\
Periódicos
\end{tabular}

Fonte: Dados da pesquisa. 
O estudo das peculiaridades de cada um dos tipos de materiais que compõe o acervo, visando a classificação contábil e, conseqüentemente, a modalidade de controle, é de grande valia, principalmente quando se trata de obras de desenvolvimento técnico-gerencial específico ou indispensáveis à execução das atividades.

Os valores encontrados para classificar os livros de alto custo de aquisição estão indicados no TAB. 9.

TABELA 9 - Livros de alto custo de aquisição - classificação

$\frac{\text { Tipos }}{\overline{\text { Acima de } \mathrm{R} \$ 500,00}}$

Foram encontrados dois parâmetros de valores para indicar a classificação do que é "alto custo de aquisição", havendo diferença de $100 \%$ de um para outro. Defende-se aqui a necessidade de se fixar um valor para esse quesito.

\subsubsection{Departamentos responsáveis pelo material bibliográfico}

No TAB.10 estão os departamentos responsáveis pelo material bibliográfico em relação às requisições de compra, aquisição, registro/classificação contábil/inventário/baixa, bem como o local indicado para o arquivamento.

TABELA 10 - Responsáveis pelo material bibliográfico

\begin{tabular}{|c|c|c|c|}
\hline $\begin{array}{c}\text { Responsáveis pelo material } \\
\text { bibliográfico }\end{array}$ & Biblioteca & $\begin{array}{c}\text { Setor de } \\
\text { Patrimônio }\end{array}$ & $\begin{array}{l}\text { Biblioteca } \\
\text { e Setor de } \\
\text { Patrimônio }\end{array}$ \\
\hline 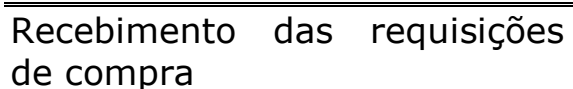 & $\bar{x}$ & $x$ & \\
\hline $\begin{array}{l}\text { Aquisição } \\
\text { Reqistro/Classificacão }\end{array}$ & $X$ & & $x$ \\
\hline contábil/Inventário/Baixa & $\begin{array}{l}x \\
x\end{array}$ & $x$ & $X$ \\
\hline
\end{tabular}

Fonte: Dados da pesquisa.

Todos os itens são afetos à biblioteca, como era de se esperar. Observou-se que, em relação às requisições de compra, algumas são de responsabilidade do setor de patrimônio. Neste sentido, acredita-se que, independente do tipo de material bibliográfico, as requisições devam também passar pela biblioteca, principalmente pelos seguintes motivos: conhecimento do mercado editorial, dos editores, dos produtos similares, dos diversos fatores que influenciam a identificação das obras publicadas (edições, tomos etc.), das diversas alternativas de acesso às fontes (empréstimo entre bibliotecas e doações), entre outros. Tudo isso pode 
agregar valor e trazer benefícios às instituições na administração e gasto do dinheiro público.

É necessário ter em mente a determinação dos departamentos responsáveis pelo recebimento das requisições de compra, aquisição, registro/classificação contábil/inventário/baixa e local de arquivamento, levando-se em conta os usos e peculiaridades de cada tipo de material bibliográfico.

\subsubsection{Obras classificadas como de desenvolvimento técnico-gerencial específico ou indispensáveis à execução das atividades}

Os departamentos responsáveis pelo material bibliográfico em relação às requisições de compra, aquisição, controle/registro, bem como o local indicado para arquivamento, estão dispostos no TAB.11.

TABELA 11 - Responsáveis pelo material indispensável à execução das atividades ou para desenvolvimento técnico gerencial específico

\begin{tabular}{lccccc}
\hline \hline $\begin{array}{c}\text { Departamento } \\
\text { responsável }\end{array}$ & Biblioteca & $\begin{array}{c}\text { Setor de } \\
\text { Patrimônio }\end{array}$ & $\begin{array}{c}\text { Biblioteca e } \\
\text { Setor de } \\
\text { Patrimônio }\end{array}$ & $\begin{array}{c}\text { Programa que } \\
\text { recebe } \\
\text { eletronicamente } \\
\text { as solicitações }\end{array}$ & $\begin{array}{c}\text { Fora da } \\
\text { biblioteca / } \\
\text { Departamentos } \\
\text { solicitantes }\end{array}$ \\
\hline \hline $\begin{array}{l}\text { Local de envio das } \\
\text { requisições de } \\
\text { compra }\end{array}$ & $\mathrm{X}$ & & & $\mathrm{X}$ & \\
Aquisição & $\mathrm{X}$ & & $\mathrm{X}$ & & \\
$\begin{array}{l}\text { Controle/registro } \\
\text { Local de }\end{array}$ & $\mathrm{X}$ & $\mathrm{X}$ & & & $\mathrm{X}$ \\
arquivamento & & & & & \\
\hline \hline
\end{tabular}

Fonte: Dados da pesquisa.

Quanto ao local de arquivamento das obras indispensáveis à execução das atividades ou para desenvolvimento técnico gerencial específico adquiridas para gabinetes, verifica-se, como esperado, seu arquivamento fora da biblioteca.

Ressalta-se a importância de análise com mais profundidade, principalmente no âmbito público, da designação de responsabilidade da biblioteca em relação às aquisições de materiais que não ficarão arquivados em seu recinto.

Além dos dados apresentados no Quadro 10, foram citadas especificamente, as enciclopédias e grandes coleções como materiais bibliográficos não classificados como obras de desenvolvimento técnico gerencial específico ou indispensáveis à execução das atividades.

As formas de controle/registro de obras de desenvolvimento técnico gerencial específico ou indispensáveis à execução das atividades foram o registro patrimonial/tombamento e o registro simplificado.

As obras de desenvolvimento técnico gerencial específico ou indispensáveis à execução das atividades foram classificados como bens de consumo, bens de consumo (uso duradouro) e bens permanentes. 
A disponibilização de obras de desenvolvimento técnico gerencial específico ou indispensáveis à execução das atividades a departamento específico foi feita sob a forma de aquisição para envio direto ao departamento, ou aquisição para a biblioteca via empréstimo permanente ou especial para o solicitante.

A forma descrita para disponibilização, a departamento específico, de obras indispensáveis à execução das atividades foi através de empréstimo especial por um ano, renovável a cada 12 meses.

A adoção de termo de responsabilidade para disponibilização das obras de desenvolvimento técnico gerencial específico ou indispensáveis à execução das atividades, bem como a devolução das obras em caso de ausência prolongada e aposentadoria, assim como para doação, são pontos identificados na análise de conteúdo.

Acredita-se que as discussões sobre as obras de desenvolvimento técnico- gerencial específico ou indispensáveis à execução das atividades são de extrema importância, assim sendo, devem ser tratadas à parte e com muita cautela.

\subsubsection{Desfazimento de materiais bibliográficos}

Nas operações de gerenciamento de materiais, a administração irá destiná-los, da forma "mais conveniente ao interesse público". Para isso, é mister classificar contabilmente o acervo, regulamentar e padronizar os procedimentos de avaliação periódica de coleções (inventário), bem como determinar as políticas e critérios de desbastamento e desfazimento dos materiais (remanejamento, transferência, cessão, alienação, inutilização, abandono etc.).

Entre os atos normativos recebidos, o Tribunal Regional Federal da $4^{a}$ Região enviou ato normativo específico para o desfazimento de materiais (IN no 40-A-01), que visa:

1. Racionalizar a destinação e o uso de materiais sob domínio e responsabilidade do Tribunal Regional Federal e Seções Judiciárias da $4^{\mathrm{a}}$ Região mediante redistribuição ou reaproveitamento.

2. Regulamentar e padronizar os procedimentos de desfazimento de materiais no âmbito da Justiça Federal da $4^{a}$ Região, segundo fundamentado interesse público.

3. Promover a alienação de materiais considerados inservíveis ou, conforme o caso, a sua destinação a processos de reciclagem, contribuindo com as políticas públicas de desenvolvimento social e de meio-ambiente (BRASIL, 2003a).

O mesmo tribunal enviou também a IN-42-D-01 que trata dos Serviços de Biblioteca, e entre os assuntos tratados no módulo 4 - Rotinas (procedimentos que compõem o Sistema de Serviços de Biblioteca), está 
elencado o "Descarte". Já no módulo 5, que se refere especificamente ao "Descarte do Material Bibliográfico", é indicada a IN no 40-A-01.

Destacam-se, entre os atos gerais analisados, os que abordam 0 tema:

a) Resolução no 384/2004 do CJF - aborda os requisitos para descarte e as formas para desfazimento do material bibliográfico, seja por doação ou venda como papel inservível, para fins de reciclagem;

b) Ato no 47/2006 do STJ - em seu Capítulo VIII "Alienação, Cessão e Transferência de Material" classifica o material inservível, trata da descarga patrimonial, da inutilização ou abandono, do inventário, dos materiais a serem alienados ou cedidos, do recolhimento ao Tesouro Nacional dos recursos provenientes da venda de material, e da necessidade de registrar no sistema administrativo do órgão, bem como no Siafi, a venda, permuta, cessão e doação de materiais.

Ressalta-se que o Decreto $n^{\circ}$ 99.658/1990 regulamenta, no âmbito da Administração Pública Federal, o reaproveitamento, a movimentação, a alienação e outras formas de desfazimento de material (BRASIL, 1990), e que a Instrução Normativa $n^{\circ}$ 205/1988 objetiva a racionalização, com minimização de custos, do uso de material no âmbito do SISG, tratando da "Cessão e Alienação" dos materiais (BRASIL, 1988).

\section{Conclusões}

O artigo 18 da Lei no 10.753/2003, estabeleceu que, com a finalidade de controlar os bens patrimoniais das bibliotecas públicas, "o livro não é considerado material permanente". Tal legislação não deveria ter sido objeto de "conflitos e dilemas", quanto à escolha da modalidade de classificação adequada do acervo de biblioteca de órgãos judiciários (como de consumo ou permanente), isso se for levada em consideração que tais bibliotecas são enquadradas como especializadas.

A Secretaria do Tesouro Nacional emitiu parecer constante no Sistema Integrado de Administração Financeira do Governo Federal SIAFI em 19 de dezembro de 2003, e reproduziu, em seu item 2.1.1 o conceito de biblioteca pública, já descrito anteriormente. Além disso, dispõe que as bibliotecas que não se enquadram como públicas deverão observar o seguinte:

3.8 - As aquisições que não se destinarem às bibliotecas públicas deverão manter os procedimentos de aquisição e classificação na natureza de despesa 449052 - Material Permanente - incorporando ao patrimônio na conta - Coleções e Materiais Bibliográficos - (1.4.2.1.2.18.00), utilizando-se o evento 51.0.145 (aquisições sem contrato) ou o 51.0.187 (aquisições com contrato) (BRASIL, 2003c, grifos nossos). 
Diante do exposto, tomando-se por base que as bibliotecas dos órgãos do judiciário não são enquadradas como públicas, conclui-se então que as aquisições de material bibliográfico (tanto para as bibliotecas como para as outras unidades administrativas), sejam classificadas como Material Permanente, não se enquadrando ao disposto no artigo 18 da Lei no 10.753/2003. Ressalta-se que tal entendimento não está explicitado no parecer em questão.

Entretanto, continuam as necessidades que visam sanar as dúvidas e padronizar procedimentos relativos à classificação de acervos.

Comunga-se, neste trabalho, que deve ser observado o disposto na Mensagem no 767192, de 27/11/2003:

As peculiaridades e finalidades dos bens com vistas à adoção de procedimentos referentes à classificação orçamentária/contábil, a modalidade de controle e as medidas a serem tomadas mediante extravio de bem (BRASIL, 2003c).

Espera-se aqui, ter abordado as discussões em relação às bibliotecas e demais órgãos do poder judiciário sobre os dispostos no art. 18 da Lei no 10.753/2003 e no Parecer de 19 de dezembro de 2003 da STN. Pode-se inferir que tanto a lei como o parecer são claros, mas não explícitos em relação ao tema abordado.

Mas se as atenções se voltarem para o entendimento das peculiaridades e finalidades dos materiais bibliográficos espera-se, com este trabalho, que as discussões e estudos possam levar à definição, adoção e padronização de procedimentos adequados à classificação orçamentária e contábil dos materiais bibliográficos (permanentes, consumo e consumo de uso duradouro). Tudo isso influenciará nas modalidades de controle $e$, conseqüentemente, nos procedimentos de aquisição, empréstimo, registro, tombamento, desbastamento e descarte. O resultado final poderia, talvez, levar à edição de normas que, mesmo sendo biblioteca ou unidade do judiciário enquadrada como especializada, permitissem, por exemplo, que códigos fossem adquiridos para os gabinetes, já que são materiais indispensáveis à execução das atividades, e classificados como bens de consumo, levando à adoção de procedimentos mais simplificados para registro, além de outras conseqüências diretas e indiretas de tal opção. Uma vitória? Acredita-se que existam profissionais que digam sim, e outros digam não. Em nossa opinião, sim!

\section{Considerações finais}

Estudos sobre a classificação e contabilização do acervo bibliográfico deverão sinalizar para a necessidade de discussão por um grupo multidisciplinar de bibliotecários, contabilistas e financistas visando melhor classificar as despesas com o acervo bibliográfico e, assim, obter mais eficiência na gestão dos recursos e maior acurácia na representação patrimonial. 
Mesmo, por vezes, acreditando-se que a classificação de material bibliográfico como de consumo, consumo de uso duradouro ou permanente, possa ser subjetiva, levando-se em consideração a duração maior ou menor que dois anos, acredita-se na necessidade de tais parâmetros para uma flexibilidade contábil/financeira que facilite e agilize a produção do conhecimento visando a tomada de decisões dos gestores públicos, sem se esquecer, contudo, da preservação do acervo.

Reitera-se a importância da colocação presente na mensagem do SIAFI onde "devem ser observadas, em complementação à legislação, as peculiaridades e finalidades dos bens com vistas à adoção de procedimentos referentes à classificação orçamentária/contábil, à modalidade de controle" (BRASIL, 2003c).

De igual importância são as encontradas nos Esclarecimentos do TST que enfatizam a necessidade de se entender se a "biblioteca do órgão se enquadra no conceito de biblioteca pública", levando-se em conta as bibliotecas de órgãos da administração pública, e da importância de se analisar "a finalidade dos materiais bibliográficos (ex.: acervo da biblioteca; uso geral da biblioteca; demais unidades administrativas) e suas peculiaridades (ex.: raridade, valor), a fim de adotar os procedimentos adequados à correta classificação contábil" (BRASIL, 2004c).

Discussões e estudos sobre a classificação e registro contábeis de materiais bibliográficos, deverão abordar também os seguintes temas: classificação e tratamento administrativo e contábil das obras de desenvolvimento técnico gerencial específico ou indispensáveis à execução das atividades, bem como a determinação dos departamentos responsáveis pelos recebimento das requisições da aquisição, controle e registro; materiais que serão integrados unicamente ao acervo da biblioteca para uso comum; adoção de critérios para o controle simplificado ou patrimonial, bem como os órgãos responsáveis por ele; confecção e adoção de termos de responsabilidade; necessidade ou não de tombamento; e políticas de desbastamento e descarte.

Acredita-se que as pesquisas sobre o tema também sejam relevantes para as bibliotecas privadas de escritórios de advocacia, entre outras, levando-se em consideração que nessas instituições o acervo poderá ter caráter permanente, de consumo e de investimento (obras de arte ou de alto custo). Tais informações ainda poderão ser úteis para a definição de previsão de um caixa mínimo e de budget para aquisição e renovação de tais acervos e coleções, auxiliando os setores contábeis e financeiros nessa tarefa, independente do tipo de biblioteca (pública ou privada).

Ressalta-se a existência de legislações, atos e jurisprudências que foram citadas nos documentos analisados e não foram analisadas e/ou recuperadas a tempo: Lei no 8.666/1993; Resolução CFC no 750; Processo administrativo no 0601/2004; Processo no 2004160902; Processo administrativo no 96.30.01921-3/1996; Processo administrativo no 01.30.00830-3/2001; Processo administrativo no 02.04.00004-1/2002; e Mensagem SRCONT no 775334/2003. 
A seleção dos pontos a serem analisados sobre o assunto, objetivo desse trabalho, foi realizada. Mesmo assim, vale ressaltar que o número reduzido de órgãos do judiciário selecionados para a pesquisa, e o não envio de e-mails também para o departamento contábil, bem como a quantidade de informações coletadas, não possibilitou um tratamento numérico/estatístico, principalmente das questões descritas nos itens 9.2.2 a 9.2.5.

Espera-se, com esta pesquisa, chamar a atenção para a necessidade de estudos científicos sobre o assunto iniciando um processo que vise suprir a lacuna existente na literatura auxiliando os profissionais que lidam com esta área e necessitam de tais informações para a definição e adoção de critérios relativos à classificação dos acervos bibliográficos.

Sugere-se, como futuros tópicos de pesquisa, as tendências de classificação, controle, registro, tombamento, desbastamento e descarte de acervos bibliográficos, bem como as repercussões de cada uma das escolhas. Acredita-se que poderão ser de extrema relevância para embasarem as previsões e decisões visando uma uniformização e, até mesmo, a possibilidade de diferenciação para cada tipo de biblioteca, acervo, uso etc.

\section{Referências}

A BIBLIOTECA pública: administração, organização, serviços. Rio de Janeiro: Fundação Biblioteca Nacional, O Departamento, 1995 apud ARRUDA, Susana Margaret de; CHAGAS, Joseane. Glossário de Biblioteconomia e Ciências afins. Florianópolis: Cidade Futura, 2002.

ARRUDA, Susana Margaret de; CHAGAS, Joseane. Glossário de Biblioteconomia e Ciências afins. Florianópolis: Cidade Futura, 2002.

BARRETO, A. A. A oferta e a demanda da informação: condições técnicas, econômicas e políticas. Disponível em: <http://www.eiasi.org.br/cinfor/sensivel.htm>. Acesso em: 14 set. 2005 apud PEREIRA, Mariland Pires. Biblioteca como recurso estratégico no escritório de advocacia. Revista Digital de Biblioteconomia e Ciência da Informação, Campinas, v. 4, n. 1, p. 19-37, jul./dez. 2006.

BRASIL. Decreto no 99.658, de 30 de outubro de 1990. Regulamenta, no âmbito da Administração Pública Federal, o reaproveitamento, a movimentação, a alienação e outras formas de desfazimento de material. Diário Oficial da União, de 31 out. 1990.

BRASIL. Lei no 10.753 de 2003, de 31 de outubro de 2003. Institui a Política Nacional do Livro. Diário Oficial da União, de 31 out. 2003b.

BRASIL. Conselho Federal da Justiça. Resolução no 384, de 05 de julho de 2004. Dispõe sobre a aquisição, classificação patrimonial e controle de obras bibliográficas no âmbito do Conselho e da Justiça Federal de primeiro e segundo graus. Diário Oficial da União, 7 jul. 2004a. Seção 1, p. 114. 
BRASIL. Conselho Federal da Justiça. Resolução no 420, de 08 de março de 2005. Altera os artigos $3^{\circ}$ e $5^{\circ}$ da Resolução no 384, de 05 de julho de 2004, que dispõe sobre a aquisição, classificação patrimonial e controle de obras bibliográficas no âmbito do Conselho e da Justiça Federal de primeiro e segundo graus. Diário Oficial da União, 10 mar. 2005. Seção 1, p. 200.

BRASIL. Ministério da Fazenda. Secretaria do Tesouro Nacional. Parecer $\mathrm{s} / \mathrm{n}^{\circ}$ de 19 de dezembro de 2003. Refere-se aos procedimentos a serem efetuados na aquisição e classificação de material bibliográfico das bibliotecas públicas, visando atender ao artigo 18 da lei 10.753, de 31/10/2003c. [mensagem pessoal]. Mensagem recebida por: <nilceia.bh@gaiasilvarolim.com.br> em 15 mar. 2007.

BRASIL. Ministério da Fazenda. Secretaria do Tesouro Nacional. Sistema Integrado de Administração Financeira do Governo Federal - SIAFI. Mensagem no 767192, de 27 de novembro de 2003b. Procedimentos contábeis para materiais bibliográficos. Lei 10.753. [mensagem pessoal]. Mensagem recebida por: <nilceia.bh@gaiasilvarolim.com.br> em 26 fev. 2007.

BRASIL. Secretaria de Administração Pública. Instrução Normativa $\mathrm{n}^{\circ}$ 205/1988. Objetiva a racionalização, com minimização de custos, do uso de material no âmbito do SISG. Disponível em: <www2.mre.gov.br/ciset/in205.doc>. Acesso em: 10 mar. 2007.

BRASIL. Superior Tribunal de Justiça. Presidência. Ato no 47, de 16 de março de 2006. Define normas gerais sobre administração de material e patrimônio no âmbito do Superior Tribunal de Justiça. Boletim de Serviço [do] ST], 17 mar. 2006.

BRASIL. Superior Tribunal de Justiça. Presidência. Ato no 213, de 30 de setembro de 2005. Dispõe sobre a aquisição e controle de obras bibliográficas no âmbito do Superior Tribunal de Justiça. [mensagem pessoal]. Mensagem recebida por: <nilceia.bh@gaiasilvarolim.com.br> em 26 fev. 2007.

BRASIL. Tribunal Regional do Trabalho da $3^{a}$ Região. Regulamento Interno da Biblioteca. Biblioteca Juiz Cândido Gomes de Freitas, Belo Horizonte, 2000. Disponível

em: <http://www2.mg.trt.gov.br/servicos/biblioteca/regbibli.htm>. Acesso em: 25 fev. 2007.

BRASIL. Tribunal Regional do Trabalho da $18^{a}$ Região. Portaria GP/GDG No 282, de 11 de maio de 2004b. Disponível em: <http://www.trt18.gov.br/revista/01AtosNormativos/NormasInternas/Por GDG04282.htm>. Acesso em: 25 fev. 2007. [mensagem pessoal]. Mensagem recebida por: <nilceia.bh@gaiasilvarolim.com.br> em 27 fev. 2007. 
BRASIL. Tribunal Regional do Trabalho da 22a Região. Ato no 152, de 2004. [mensagem pessoal]. Mensagem recebida por: <nilceia.bh@gaiasilvarolim.com.br> em 28 fev. 2007.

BRASIL. Tribunal Regional do Trabalho da 24a Região. Ato GP/DGCA/DI no 69, de 2004. [mensagem pessoal]. Mensagem recebida por: <nilceia.bh@gaiasilvarolim.com.br> em 5 mar. 2007.

BRASIL. Tribunal Regional Federal da $4^{a}$ Região. Instrução Normativa No 40-A-01, de 21 de março de 1997, revista em 6/2003. Desfazimento de materiais. Boletim Eletrônico, n. 164, 10 jun. 2003a.

BRASIL. Tribunal Regional Federal da $4^{a}$ Região. Instrução Normativa No 42-D-01, de 30 de março de 1999. Serviços de Bibliotecas. Tem por finalidade determinar e disciplinar métodos e procedimentos relativos ao funcionamento da Biblioteca do Tribunal Regional Federal da $4^{a}$ Região. Boletim Eletrônico, n. 113, 30 mar. 1999.

BRASIL. Tribunal Superior do Trabalho. Secretaria de Orçamento e Finanças. Serviço de Contabilidade. Esclarecimentos sobre a classificação de material bibliográfico, de 12 de fevereiro de 2004c. [mensagem pessoal]. Mensagem recebida por: <nilceia.bh@gaiasilvarolim.com.br> em 5 mar. 2007.

CONTABILIDADE introdutória. Equipe de professores da Faculdade de Economia, Administração e Contabilidade da USP. 9. ed. São Paulo: Atlas, 1998.

FULLIN, Camila Barleta. Perspectivas futuras para a demanda de profissionais da informação jurídica nos escritórios de advocacia em Campinas. Revista Digital de Biblioteconomia e Ciência da Informação, Campinas, v. 3, n. 2, p. 31-42, jan./jun. 2006.

GRECO, Alvísio; AREND, Lauro. Contabilidade: teoria e prática básicas. 7. ed. Porto Alegre: Sagra Luzzatto, 1997.

IUDÍCIBUS, Sérgio de; MARTINS, Eliseu; GELBCKE, Ernesto Rubens. Manual de contabilidade das sociedades por ações: aplicável às demais sociedades. 6. ed. ver. atual. São Paulo: Atlas, 2003.

MACIEL, Alba Costa; MENDONÇA, Marília Alvarenga Rocha. Bibliotecas como organizações. Rio de Janeiro: Interciência, 2000.

MARION, José Carlos. Contabilidade básica. 7. ed. ampl. e atual. São Paulo: Atlas, 2004.

PASSOS, E. Bibliotecário jurídico: seu perfil, seu papel. Disponível em: <http://infolegis.com.br/perfilbibjuridico.htm>. Acesso em: 9 out. 2003 apud FULLIN, Camila Barleta. Perspectivas futuras para a demanda de profissionais da informação jurídica nos escritórios de advocacia em Campinas. Revista Digital de Biblioteconomia e Ciência da Informação, Campinas, v. 3, n. 2, p. 31-42, jan./jun. 2006. 
PEREIRA, Mariland Pires. Biblioteca como recurso estratégico no escritório de advocacia. Revista Digital de Biblioteconomia e Ciência da Informação, Campinas, v. 4, n. 1, p. 19-37, jul./dez. 2006.

PISCITELLI, Roberto Bocaccio; TIMBÓ, Maria Zulene Farias; ROSA, Maria Berenice. Contabilidade Pública: uma abordagem da administração financeira pública. 6. ed. São Paulo: Atlas, 1999.

REZENDE, Martha Izabel de Souza Duarte. Gerenciamento da informação e do conhecimento jurídico. Disponível em: <http://www.prgo.mpf.gov.br/doutrina/MARTHA-13.htm>. Acesso em: 28 out. 2003 apud FULLIN, Camila Barleta. Perspectivas futuras para a demanda de profissionais da informação jurídica nos escritórios de advocacia em Campinas. Revista Digital de Biblioteconomia e Ciência da Informação, Campinas, v. 3, n. 2, p. 31-42, jan./jun. 2006.

ROMANI, Claudia; BORSZCZ, Iraci. Unidades de Informação: conceitos e competências. Florianópolis: Ed. UFSC, 2006.

SÁ, A. Lopes de; SÁ, A. M. Lopes de. Dicionário de contabilidade. 9. ed. São Paulo: Atlas, 1995.

SILVA, Lino Martins da. Contabilidade governamental: um enfoque administrativo. 7. ed. São Paulo: Atlas, 2004.

Agradecemos a revisão e sugestões de Solange M. Souza Macedo, bibliotecária da Faculdade Novos Horizontes, bem como as preciosas avaliações e sugestões do comitê do SNIDJ. Agradecimentos especiais a todos os bibliotecários que participaram da pesquisa. 